\title{
Growth hormone does not stimulate early healing in rat tendons
}

Therese Andersson, Pernilla Eliasson and Per Aspenberg

\section{Linköping University Post Print}

N.B.: When citing this work, cite the original article.

Original Publication:

Therese Andersson, Pernilla Eliasson and Per Aspenberg, Growth hormone does not stimulate early healing in rat tendons, 2012, International Journal of Sports Medicine, (33), 3, 240-243. http://dx.doi.org/10.1055/s-0031-1291324

Copyright: Thieme Publishing / Georg Thieme Verlag http://www.thieme.com/

Postprint available at: Linköping University Electronic Press http://urn.kb.se/resolve?urn=urn:nbn:se:liu:diva-76085 
Growth Hormone does not stimulate early healing in rat tendons

Therese Andersson, Pernilla Eliasson, Per Aspenberg 


\begin{abstract}
Growth Hormone stimulates bone growth and fracture repair. It acts mainly by increasing the systemic levels of IGF-1. Local treatment with IGF-1 appears to stimulate tendon healing. We therefore hypothesized that systemic treatment with Growth Hormone would also stimulate tendon healing. Rat Achilles tendons were transected and left to heal. Four groups were studied. Intramuscular injections of botulinum toxin A (Botox) were used to reduce loading in 2 groups. The animals were randomized to twice daily injections of Growth Hormone $(\mathrm{n}=2 \times 10)$ or saline $(\mathrm{n}=2 \times 10)$, and killed after 10 days. Healing was assessed by mechanical testing. Muscle paralysis induced by Botox reduced the strength of the healing tendon by two thirds. Growth Hormone increased femoral and tibial length in the unloaded, and femoral and tibial weight in the loaded group. Body weight and muscle weight were increased in both. In contrast, there was no increase in the strength of the healing tendons, regardless of mechanical loading status. An increase in peak force of the loaded healing tendons by more than $5 \%$ could be excluded with $95 \%$ confidence. In spite of its stimulatory effects on other tissues, Growth Hormone did not appear to stimulate tendon or tendon repair.
\end{abstract}




\section{Introduction}

Administration of Growth Hormone $(\mathrm{GH})$ stimulates growth of both muscles and bones. It has also been suggested that Growth Hormone plays an anabolic role in the connective tissue component of skeletal muscles and tendons. Growth Hormone administration to GH-deficient dwarf rats for 14 days induced a higher collagen turnover in intact patellar tendons and medial and lateral collateral ligaments, but the total amount of collagen was unchanged [19]. Growth Hormone stimulates collagen expression and synthesis in human tendons [11] although it was recently shown that administration of a Growth Hormone receptor blocker has no effect on collagen synthesis in human tendons [20]. Growth Hormone induces the production of insulin-like growth factor-1 (IGF-1), and its effect on tendon metabolism might be mediated via this growth factor. IGF-1 is primarily produced by the liver, but can also be expressed locally, both in tendons and muscles. IGF-1 stimulates matrix synthesis and cell proliferation in flexor tendon explants from rabbits $[1,16]$. Furthermore, a study in humans demonstrated that the expression of IGF-1 in the patellar tendon was up-regulated and collagen synthesis was increased when Growth Hormone was given systemically [11].

Very little information related to Growth Hormone and tendon healing can be found in the literature. A study on the effect of Growth Hormone on the healing of superficial flexor tendonitis in horses showed no positive effect; in fact a slight negative effect was seen [12]. In contrast, several animal studies have demonstrated up-regulation of the IGF-1 expression during tendon healing $[6,7,9]$. This up-regulation was seen both during an early and a later phase of healing. Moreover, local IGF-1 treatment following Achilles tendon transection in rats resulted in faster functional recovery compared to controls 14 days after transection [18]. Local IGF-1 treatment also increased cell proliferation and collagen content in collagenaseinduced tendon lesions in horses [10]. However, no positive effect on the mechanical or 
material properties after local IGF-1 treatment could be demonstrated 8 weeks after creation of the lesions.

The effect of systemic Growth Hormone on ligament healing in rats has been evaluated in detail, and no significant effect on the mechanical or material properties of the healing, loaded or unloaded, ligaments was seen 3 weeks after surgery [21] .

Studies concerning the effect of Growth Hormone on fracture healing are abundant in the literature. Several studies have shown that Growth Hormone has positive effects on fracture healing [4, 17, 22-24]. There are, however, contradicting results, and the outcome of treatment seems to depend on model, dose, time-point and duration of administration $[3,5$, 8].

Taken together, IGF-1 might be important for tendon tissue maintenance, remodelling and repair. Since Growth Hormone exerts many of its effects via IGF-1, and is known to stimulate growth of other tissues, and even fracture healing, we hypothesized that systemic Growth Hormone treatment would improve tendon healing in rats. In the present study, the effect of Growth Hormone was evaluated by mechanical testing in both loaded and unloaded healing Achilles tendons. 


\section{Materials and Methods}

\section{Experimental overview}

This study was performed in two parts; one where we tested the effect of Growth Hormone on mechanically loaded healing tendons in rats, and one where the loading of the healing tendons was reduced. Intramuscular injections of botulinum toxin A (Botox) were used to reduce loading. The right Achilles tendon was then transected and left to heal. Daily Growth Hormone injections were given subcutaneously. Ten days after surgery, the tendons were mechanically tested to evaluate the effect of Growth Hormone on the healing process.

\section{Animals}

Forty female Sprague-Dawley rats (Scanbur BK, Stockholm, Sweden), weighing approximately $220 \mathrm{~g}$, were used. They were housed two per cage at $21^{\circ} \mathrm{C}$ in a 12 -h light and dark cycle, and given food and water ad libitium. The study was approved by the Regional Ethics Committee for Animal Experiments and adhered to the institutional guidelines for the care and treatment of laboratory animals. The ethical standards of the journal [14] were followed.

\section{Botox injections}

Twenty rats were used to study the effect of Growth Hormone on unloaded healing tendons. The rats were anesthetised with isoflurane gas (Forene, Abbot Scandinavia, Solna, Sweden) and their right hind limb was shaved. Botox (Botox, Allergan, Irvine, CA) was injected into the gastrocnemius lateralis and medianus and the soleus muscle (1 U per muscle). The rats were then operated on day five after the Botox injections. By then, the rats were unable to actively plantar-flex the ankle joint, and loaded the entire foot for each step. 
Surgery

All 40 rats were anesthetised with isoflurane gas and given antibiotics (Engemycin; Intervet, Boxmeer, Holland), and analgesics (Temgesic; Schering-Plough, Brussels, Belgium) preoperatively. The surgery was performed under aseptic conditions. A transverse incision was made in the skin lateral to the right Achilles tendon. The plantaris tendon was removed and the Achilles tendon was cut transversely. A 3-mm segment of the Achilles tendon was removed and the wound was closed leaving the tendon unsutured.

\section{Growth Hormone treatment}

Ten animals from the loaded group (no botox injections) and ten animals from the unloaded group (botox injections) received daily Growth Hormone injections (Nutropin Aq, Institut Produits Synthèse (IPSEN) AB, Kista, Sweden). The treatment started the day after surgery and the animals were given subcutaneous injections twice a day at 8 am and $5 \mathrm{pm}$. The total daily dose was $2 \mathrm{mg} / \mathrm{kg}$ body weight, divided into two equal doses. The animals in the control groups were given saline subcutaneously twice a day.

\section{Mechanical testing and growth assessment}

The animals were euthanized with $\mathrm{CO}_{2}$ gas 10 days after surgery, and the healing and intact tendons were harvested for mechanical testing. The tendons with the attached calcaneal bone were dissected free together with parts of the gastrocnemius and soleus muscle complex. Sagittal and transverse diameters of the midpart of the callus tissue or intact tendon were measured with a slide caliper. Cross sectional area was calculated by assuming an elliptical shape of the transverse section. The tendons were fixated in a metal clamp [2] and the distance between the clamp and the calcaneus was used as an approximation of tendon length. Finally the tendons were mounted vertically [2] in a materials testing machine (100R; 
DDL Inc., Eden Praire MN) and were distracted until failure at a constant speed of $0.1 \mathrm{~mm} / \mathrm{s}$. Force at failure and stiffness were calculated by the software of the testing machine. The investigator marked a linear portion of the elastic phase of the curve for stiffness calculation. Elastic modulus and ultimate stress were calculated.

The left calf muscle, tibia and femur were weighed and the length of the bones was measured to confirm an overall effect of the Growth Hormone treatment.

\section{Statistics}

All evaluation was performed while blinded. The results from the loaded and the unloaded healing tendons were analyzed separately with Student's t-test. The results from the intact tendons were analyzed in the same way. Peak force was regarded as the primary outcome variable. Mann-Whitney U test was used to analyse the body weight results. Data were evaluated using SPSS for Windows, Rel. 15.0.0. 2006. Chicago: SPSS Inc.

\section{Results}

In all cases, tendon continuity was restored by a fibrous callus filling the defect between the stumps. At testing, all tendons ruptured in this mid-substance, except for two tendons, one from each loaded group, which ruptured near the metal clamp.

\section{Loaded tendons}

The peak force of the healing tendons was unaffected by the treatment, and the $95 \%$ confidence interval for the peak force excludes an increase after Growth Hormone treatment by more than $5 \%$ (Table 1). The stiffness in the healing tendons was decreased by the 
Table 1. Mechanical properties of healing tendons 10 days after transaction, and contralateral intact tendons. Treatment effects are described as percent change from control $(95 \% \mathrm{CI})$. An effect of hormone treatment changing peak force by more than $22 \%$ can thus be excluded with $95 \%$ confidence.

\begin{tabular}{|c|c|c|c|c|c|c|}
\hline \multirow[b]{3}{*}{ Healing side } & \multicolumn{3}{|c|}{ Loaded healing } & \multicolumn{3}{|c|}{ Unloaded healing } \\
\hline & Control & $\begin{array}{c}\text { Growth } \\
\text { hormone }\end{array}$ & $\begin{array}{c}\text { Treatment effect } \\
(\%)\end{array}$ & Control & $\begin{array}{c}\text { Growth } \\
\text { hormone }\end{array}$ & $\begin{array}{c}\text { Treatment effect } \\
(\%)\end{array}$ \\
\hline & Mean \pm SD & Mean \pm SD & $95 \% \mathrm{CI}$ & Mean \pm SD & Mean \pm SD & $95 \% \mathrm{CI}$ \\
\hline $\begin{array}{l}\text { Cross sectional area } \\
\left(\mathrm{mm}^{2}\right)\end{array}$ & $9.4 \pm 1.8$ & $8.5 \pm 1.6$ & -28 to 70 & $5.7 \pm 0.6$ & $5.7 \pm 1.1$ & -14 to 15 \\
\hline Peak force $(\mathrm{N})$ & $37 \pm 5.3$ & $33 \pm 5.7$ & -22 to 5.2 & $11 \pm 2.1$ & $11 \pm 2.5$ & -18 to 22 \\
\hline Peak stress (MPa) & $4.0 \pm 1.0$ & $4.0 \pm 0.8$ & -22 to 22 & $2.0 \pm 0.44$ & $2.0 \pm 0.38$ & -18 to 21 \\
\hline Stiffness (N/mm) & $9.3 \pm 1.4$ & $7.8 \pm 1.0^{\mathrm{a}}$ & -28 to 4.1 & $6.2 \pm 1.1$ & $6.0 \pm 0.91$ & -17 to 13 \\
\hline Elastic modulus (MPa) & $15 \pm 3.7$ & $15 \pm 4.2$ & -25 to 25 & $6.2 \pm 1.4$ & $6.0 \pm 1.2$ & -22 to 17 \\
\hline \multicolumn{7}{|l|}{ Intact side (loaded) } \\
\hline $\begin{array}{l}\text { Cross sectional area } \\
\left(\mathrm{mm}^{2}\right)\end{array}$ & $1.3 \pm 0.2$ & $1.3 \pm 0.3$ & -15 to 23 & $1.6 \pm 0.3$ & $1.8 \pm 0.6$ & -18 to 40 \\
\hline Peak force $(\mathrm{N})$ & $54 \pm 6.4$ & $59 \pm 4.8$ & -1.2 to 19 & $55 \pm 11$ & $58 \pm 6.8$ & -9.5 to 22 \\
\hline Peak stress (MPa) & $42 \pm 9.1$ & $46 \pm 13$ & -16 to 33 & $36 \pm 7.8$ & $37 \pm 13$ & -25 to 32 \\
\hline Stiffness (N/mm) & $28 \pm 4.7$ & $25 \pm 1.7$ & -23 to 50 & $28 \pm 3.9$ & $27 \pm 2.7$ & -15 to 7.5 \\
\hline Elastic modulus (MPa) & $140 \pm 37$ & $140 \pm 39$ & -21 to 29 & $134 \pm 36$ & $129 \pm 37$ & -29 to 22 \\
\hline
\end{tabular}

${ }^{a}$ different from healing control $(p<0.05)$ 
hormone treatment $(\mathrm{p}=0.01$, table 1$)$ but there were no differences in the material properties (peak stress and elastic modulus) between the groups.

In the intact tendons, no effects of Growth Hormone were seen regarding mechanical properties (peak force and stiffness) or material properties. The cross sectional area was also unaffected.

In contrast to the absent effects on tendon, Growth Hormone treatment had a clear over-all anabolic effect on the rats, with a more rapid weight gain $(\mathrm{p}=0.004)$, heavier calf muscle $(p=0.009$, table 2$)$, and increased weight of the tibia $(p=0.003$, table 2$)$ and femur $(p=0.05$, table 2).

\section{Unloaded tendons}

Unloading the healing tendons markedly reduced the strength of the callus tissue. The peak force only reached one third of the values measured for the loaded tendons $(\mathrm{p}<0.0001$, table 1). Stiffness, peak stress and elastic modulus were similarly decreased ( $p<0.001$ for all parameters, table 1) by unloading.

Growth Hormone was not seen to affect the healing of unloaded tendons. The $95 \%$ confidence interval for the difference between group means excludes more than $22 \%$ increase in peak force after Growth Hormone treatment (Table 1). Also the stiffness, peak stress and elastic modulus appeared unaffected.

No effect was seen on the intact tendons; GH-treatment did not induce any measurable changes in mechanical or material properties. 
Table 2. Muscle and bone data from treated and untreated rats. Treatment effects are described as percent change from control (95\% CI).

\begin{tabular}{|l|c|c|c|c|c|c|}
\hline & \multicolumn{3}{|c|}{ Loaded group } & \multicolumn{3}{c|}{ Unloaded group } \\
\cline { 2 - 7 } & Control & $\begin{array}{c}\text { Growth } \\
\text { hormone }\end{array}$ & $\begin{array}{c}\text { Treatment effect } \\
(\%)\end{array}$ & Control & $\begin{array}{c}\text { Growth } \\
\text { hormone }\end{array}$ & $\begin{array}{c}\text { Treatment effect } \\
(\%)\end{array}$ \\
\cline { 2 - 7 } Intact side (loaded) & Mean \pm SD & Mean \pm SD & $\mathbf{9 5 \% ~ C I ~}$ & Mean \pm SD & Mean \pm SD & 95 \% CI \\
\hline $\begin{array}{l}\text { Calf muscle weight } \\
(\mathrm{g})\end{array}$ & $3.7 \pm 0.3$ & $4.1 \pm 0.3^{b}$ & 3.2 to 21 & $4.4 \pm 0.2$ & $5.2 \pm 0.3^{b}$ & 13 to 24 \\
\hline Tibia weight (mg) & $450 \pm 17$ & $490 \pm 32^{b}$ & 3.5 to 13 & $404 \pm 24$ & $416 \pm 22$ & -1.2 to 12 \\
\hline Tibia length (mm) & $34 \pm 0.5$ & $34 \pm 0.5$ & -0.3 to 3.2 & $34 \pm 0.4$ & $35 \pm 0.5^{b}$ & 1.2 to 4.2 \\
\hline Femur weight $(\mathrm{mg})$ & $563 \pm 31$ & $590 \pm 26^{b}$ & 0.05 to 10 & $505 \pm 33$ & $531 \pm 35$ & -2.4 to 8.3 \\
\hline Femur length $(\mathrm{mm})$ & $29 \pm 0.2$ & $29 \pm 0.5$ & -0.3 to 2.3 & $28 \pm 0.4$ & $29 \pm 0.5^{b}$ & 0.3 to 2.8 \\
\hline
\end{tabular}

${ }^{b}$ different from control $(p<0.05)$ 
Like in the loaded groups, Growth Hormone had an overall anabolic effect. The treated rats gained weight more rapidly ( $\mathrm{p}<0.0001$ ) and their left calf muscle (unoperated leg) was heavier $(\mathrm{p}<0.0001$, table 2$)$. The length of tibia $(\mathrm{p}=0.016$, table 2$)$ and femur $(\mathrm{p}=0.001$, table 2) were also increased. 


\section{Discussion}

Our results show that a Growth Hormone treatment regimen, which has clear and significant effects on bone and muscle, had no effects (or possibly a negative effect) on early tendon healing. However, our results agree with results demonstrated for healing ligaments [21].

In early tendon repair, local treatment with IGF-1 can improve healing. It was therefore reasonable to hypothesize that systemic Growth Hormone treatment might be efficacious, since it mainly exerts its effects via an increased local or systemic IGF-1 level. The negative results cannot be explained by a low power, since even a small positive effect could be excluded with $95 \%$ confidence ( 5 and $22 \%$, respectively). Neither could the explanation be an inadequate dose, since several positive effects were seen in muscle and bone. Moreover, a previous study has shown that Growth Hormone improves fracture healing in rats when using the current dose [4]. The remaining explanation to our results could therefore be that, for stimulation of tendon healing, pharmacological concentrations of IGF-1 are needed, and that the given Growth Hormone doses are unable to produce the required local increase in IGF-1 concentrations. However, this hypothesis should be tested by gene and protein expression studies. The absent effect on uninjured tendons was expected, as their lower turnover rate is likely to make them less responsive.

Mechanical stimulation is important for healing $[13,15,25]$. Botox can be used to reduce loading, and acts specifically on the neuromuscular junction. Reducing mechanical stimulation by paralyzing the calf muscles with Botox reduced the strength of the healing tendon by two thirds. Still, no effects of Growth Hormone were observed. This suggests that Growth Hormone or IGF-1 is not essential for the mechano-regulation of this healing process, or that they cannot substitute for lack of mechanical stimulation. The effects observed by 
others in vitro and with local treatment in vivo might therefore possibly represent pharmacological concentrations, unrelated to physiological processes.

Growth Hormone can stimulate fracture repair in rats, and the early phase of fracture repair is similar to tendon healing in that it consists of inflammation and formation of a granulationlike tissue. Our results therefore suggest that Growth Hormone might not stimulate these early processes, but exerts its effects in fractures mainly during later stages of repair, characterized by bone formation and remodeling.

Growth Hormone is being used for doping athletes, and it is conceivable that athletes are also given Growth Hormone when injured. As regards injuries to tendon, and probably ligament, our results suggest that such treatment is not only offensive, but also meaningless for promoting early tendon repair. 


\section{References}

${ }^{1}$ Abrahamsson S O, Lundborg G, Lohmander L S. Recombinant human insulin-like growth factor-I stimulates in vitro matrix synthesis and cell proliferation in rabbit flexor tendon. $\mathrm{J}$ Orthop Res 1991; 9: 495-502.

${ }^{2}$ Andersson T, Eliasson P, Aspenberg $P$. Tissue memory in healing tendons: short loading episodes stimulate healing. J Appl Physiol 2009; 107: 417-421.

${ }^{3}$ Bak B, Jorgensen P H, Andreassen T T. Dose response of growth hormone on fracture healing in the rat. Acta Orthop Scand 1990; 61: 54-57.

${ }^{4}$ Bak B, Jorgensen P H, Andreassen T T. Increased mechanical strength of healing rat tibial fractures treated with biosynthetic human growth hormone. Bone 1990; 11: 233-239.

${ }^{5}$ Bak B, Jorgensen P H, Andreassen T T. The stimulating effect of growth hormone on fracture healing is dependent on onset and duration of administration. Clin Orthop Relat Res $1991 ; 295-301$.

${ }^{6}$ Berglund M E, Hart D A, Reno C, Wiig M. Growth factor and protease expression during different phases of healing after rabbit deep flexor tendon repair. J Orthop Res 2011; 29: 886892.

${ }^{7}$ Bring D, Reno C, Renstrom P, Salo P, Hart D, Ackermann P. Prolonged immobilization compromises up-regulation of repair genes after tendon rupture in a rat model. Scand J Med Sci Sports 2010; 20: 411-417.

${ }^{8}$ Carpenter J E, Hipp J A, Gerhart T N, Rudman C G, Hayes W C, Trippel S B. Failure of growth hormone to alter the biomechanics of fracture-healing in a rabbit model. J Bone Joint Surg Am 1992; 74: 359-367.

${ }^{9}$ Chen $C H$, Cao Y, Wu Y F, Bais A J, Gao J S, Tang J B. Tendon healing in vivo: gene expression and production of multiple growth factors in early tendon healing period. J Hand Surg Am 2008; 33: 1834-1842. 
${ }^{10}$ Dahlgren L A, van der Meulen M C, Bertram J E, Starrak G S, Nixon A J. Insulin-like growth factor-I improves cellular and molecular aspects of healing in a collagenase-induced model of flexor tendinitis. J Orthop Res 2002; 20: 910-919.

${ }^{11}$ Doessing S, Heinemeier K M, Holm L, Mackey A L, Schjerling P, Rennie M, Smith K, Reitelseder S, Kappelgaard A M, Rasmussen M H, Flyvbjerg A, Kjaer M. Growth hormone stimulates the collagen synthesis in human tendon and skeletal muscle without affecting myofibrillar protein synthesis. J Physiol 2010; 588: 341-351.

${ }^{12}$ Dowling B A, Dart A J, Hodgson D R, Rose R J, Walsh W R. The effect of recombinant equine growth hormone on the biomechanical properties of healing superficial digital flexor tendons in horses. Vet Surg 2002; 31: 320-324.

${ }^{13}$ Eliasson P, Andersson T, Aspenberg P. Rat Achilles tendon healing: mechanical loading and gene expression. J Appl Physiol 2009; 107: 399-407.

${ }^{14}$ Harriss D J, Atkinson G. International Journal of Sports Medicine - ethical standards in sport and exercise science research. Int J Sports Med 2009; 30: 701-702.

${ }^{15}$ Jarvinen $M J$, Lehto $M U$. The effects of early mobilisation and immobilisation on the healing process following muscle injuries. Sports Med 1993; 15: 78-89.

${ }^{16}$ Kang H J, Kang E S. Ideal concentration of growth factors in rabbit's flexor tendon culture. Yonsei Med J 1999; 40: 26-29.

${ }^{17}$ Kolbeck S, Bail H, Schmidmaier G, Alquiza M, Raun K, Kappelgard A, Flyvbjerg A, Haas $N$, Raschke $M$. Homologous growth hormone accelerates bone healing--a biomechanical and histological study. Bone 2003; 33: 628-637.

${ }^{18}$ Kurtz C A, Loebig T G, Anderson D D, DeMeo P J, Campbell P G. Insulin-like growth factor I accelerates functional recovery from Achilles tendon injury in a rat model. Am J Sports Med 1999; 27: 363-369. 
${ }^{19}$ Kyparos A, Orth MW, Vailas A C, Martinez D A. Growth and maturational changes in dense fibrous connective tissue following 14 days of rhGH supplementation in the dwarf rat. Growth Horm IGF Res 2002; 12: 367-373.

${ }^{20}$ Nielsen R H, Doessing S, Goto K, Holm L, Reitelseder S, Agergaard J, Schjerling P, Flyvberg A, Kjaer M. GH receptor blocker administration and muscle-tendon collagen synthesis in humans. Growth Horm IGF Res 2011; 21: 140-145.

${ }^{21}$ Provenzano P P, Alejandro-Osorio A L, Grorud KW, Martinez D A, Vailas A C, Grindeland $R E$, Vanderby $R$, Jr. Systemic administration of IGF-I enhances healing in collagenous extracellular matrices: evaluation of loaded and unloaded ligaments. BMC Physiol 2007; 7: 2.

${ }^{22}$ Raschke M, Kolbeck S, Bail H, Schmidmaier G, Flyvbjerg A, Lindner T, Dahne M, Roenne I A, Haas $N$. Homologous growth hormone accelerates healing of segmental bone defects. Bone 2001; 29: 368-373.

${ }^{23}$ Raschke M, Rasmussen M H, Govender S, Segal D, Suntum M, Christiansen J S. Effects of growth hormone in patients with tibial fracture: a randomised, double-blind, placebocontrolled clinical trial. Eur J Endocrinol 2007; 156: 341-351.

${ }^{24}$ Schmidmaier G, Wildemann B, Heeger J, Gabelein T, Flyvbjerg A, Bail H J, Raschke M. Improvement of fracture healing by systemic administration of growth hormone and local application of insulin-like growth factor-1 and transforming growth factor-beta1. Bone 2002; 31: $165-172$.

${ }^{25}$ Virchenko $O$, Aspenberg $P$. How can one platelet injection after tendon injury lead to a stronger tendon after 4 weeks? Interplay between early regeneration and mechanical stimulation. Acta Orthop 2006; 77: 806-812. 